\title{
Evaluation of the joint effect of glyphosate and dimethoate using a small-scale terrestrial ecosystem
}

\author{
Miguel J.G. Santos*, Rui Morgado, Nuno Gonçalo C. Ferreira, Amadeu M.V.M. Soares, Susana Loureiro \\ Departamento de Biologia da Universidade de Aveiro and CESAM, Campus Universitário de Santiago, 3810-193 Aveiro, Portugal
}

\section{A R T I C L E I N F O}

\section{Article history:}

Received 8 February 2011

Received in revised form

31 May 2011

Accepted 2 June 2011

Available online 2 July 2011

Keywords:

Microcosm

Plant protection products

Mixtures

Independent Action

\begin{abstract}
A B S T R A C T
In the present work a small-scale terrestrial ecosystem (STEM) containing a soil collected from an agricultural field in Central Portugal was used to evaluate the effects of the combination of the herbicide glyphosate and the insecticide dimethoate. Earthworms (Eisenia andrei), isopods (Porcellionides pruinosus), turnip seeds (Brassica rapa), and bait-lamina strips were placed in the STEM. The results showed that the application of the recommended field dose of both pesticides did not cause any effect on the weight variation of earthworms and growth of the plants. The application of the herbicide, even at 5 and 10 times the field dose, increased feeding activity in soil (bait-lamina test), although the application of dimethoate led to a decrease in feeding activity in all concentrations tested. The binary mixtures performed showed that according to the Independent Action model, synergism (higher effect than expected from the single exposures) was observed in both the shoot length and fresh weight of $B$. rapa at 5 times the field dose, but antagonism was observed at 10 times the field dose. Regarding the germination success, synergism was observed at the field dose, but antagonism was detected at 5 times and 10 times the field dose. There was a decrease on the earthworm's weight in all concentrations tested, although no statistical differences were observed in any of the treatments made. Regarding depth distribution of $E$. andrei, worms were found in the upper layer more than it was predicted for all concentrations. In the mixtures with the field and 5 times the field dose there was a decrease in the feeding activity (bait-lamina consumption) by the soil fauna. From the four biomarkers assessed on the isopods (Catalase, Acetylcholinesterase, Glutathione-S-transferase, and Lipid peroxidation), only a significant decrease in the Acetylcholinesterase activity upon dimethoate and the binary mixtures exposures performed with the field dose was observed and on Lipid peroxidation at the field doses of single and binary exposures.
\end{abstract}

(c) 2011 Elsevier Inc. All rights reserved.

\section{Introduction}

Microcosms have been proposed as an optimal tool to evaluate the effects of chemicals in both structural and functional endpoints in soil ecosystems in order to achieve a greater realism in ecotoxicological evaluation of chemicals to non-target organisms (Edwards, 2002). The effects of several classes of pollutants have been tested in microcosm design experiments, using various test compartments and methodology in terms of numbers of species introduced, time period of evaluation and soil type used as exposure medium (Lukkari et al., 2006). The option for an integrated microcosm experiment should try to establish a possible link between what happens in single species exposure tests made in laboratory conditions and the effects expected in field conditions (Løkke and Van Gestel, 1998).

The application of plant protection products (PPP) in agricultural fields to control pests and achieve maximum harvest yield

\footnotetext{
* Corresponding author. Fax: +351234372 587.

E-mail address: mjsantos@ua.pt (M.J. Santos).
}

can pose threats to non-target organisms present in soil ecosystems (Giller et al., 1997). Since the majority of crops need more than just one type of PPP application during its growing cycle, this could pose an extra problem in terms of the action of combined agents to soil populations living in the vicinity of this exposure sites (Santos et al., 2010a,b). Consequently, it is important to study the effects of combined PPP to non-target organisms, such as plants, earthworms and other faunal communities present in soil ecosystems (Matsumura, 1987).

The Independent Action (IA) model has been established as a reference model for the assessment of pesticide mixtures of chemicals with different modes of action (Bliss, 1939; Köneman and Pieters, 1996; Svendsen et al., 2010). Theoretically this model assumes that the probability of the effect of one chemical is independent from the probability of the effect of the other chemical present in the mixture (Loureiro et al., 2010). However, in some mixtures, interactions between the components can occur, resulting in antagonism, when the mixture toxicity is lower than expected from the toxicities of single components, or synergism whereas the joint effects are stronger than it should be expected by the individual components toxicity (Jonker et al., 2005). 
Earthworms are responsible for the redistribution of organic material in soil, increasing soil penetrability and influence the supply of nutrients in soil ecosystems, thus contributing to the augment of soil fertility (Syers and Springett, 1984; Lavelle et al., 1997). Their importance in maintaining soil structure and function is well recognized and are considered useful indicators of soil health and quality (Edwards, 2004). Non-target plants can enter in contact with pesticide due to spray drift from agricultural fields (Marrs et al., 1989), and this exposure may lead to impairment in plant communities (Snoo and Wit, 1998). Terrestrial isopods are important litter macrodecomposers on the soil surface that assume a key role in nutrient recycling of the plant material in edaphic ecosystems, and the impact of pesticides on biochemical indicators (biomarkers) has been used to evaluate possible detrimental effects that PPP could pose to this non-target organisms (Santos et al., 2010b). The bait-lamina test was developed to assess the feeding activity of soil organisms in different ecosystems (Kratz, 1998). This method is used to assess the biological activity of the soil fauna, thus permitting to evaluate the impact of pesticides in the function of soil edaphic communities (Filzek et al., 2004).

Two PPP with different modes of action were chosen in this work: the herbicide glyphosate, which acts in plants through the inhibition of 5-enolpyruvylshikimic acid 3-phosphate (EPSP) synthase (Huangfu et al., 2007) and the insecticide dimethoate which inhibits the action of Acetylcholinesterase (AChE) enzyme activity in several invertebrates (Loureiro et al., 2005a) and in some weed seeds acts through the inhibition of the synthesis or action of hydrolytic enzymes during germination (Gange et al., 1992).

The objectives of this work were firstly to evaluate if a designed microcosm experiment could function as a potential predictive tool for assessing the effects of pesticide application in agricultural fields and secondly to evaluate the combined effects of the two pesticides to the earthworm Eisenia andrei, the terrestrial isopod Porcellionides pruinosus, the turnip species Brassica rapa and to the bait-lamina strips, using the concept of Independent Action.

\section{Materials and methods}

\subsection{Test organisms and test soil}

Earthworms of the epigeic species E. andrei (Bouché) were bought from a commercial supplier and seeds of $B$. rapa (L.) rapid cycle (Carolina Biological Supply Company) were used. Adult isopods, from a culture maintained in laboratory controlled conditions, of the species P. pruinosus $(15-25 \mathrm{mg}$ wet weight) were used with no sex differentiation, although pregnant females and animals with lack of antennae were not used in the experimental procedure.

Soil was collected from an agricultural field in the spring of 2010 (first $20 \mathrm{~cm}$ of soil) from the lower Mondego Valley (Portugal). The soil has no history of pesticide application in the last five years (Lemos et al., 2010). Soil parameters include a $\mathrm{pH}\left(\mathrm{H}_{2} \mathrm{O}\right)=7.48$, organic matter content $=2.4 \%$, clay $=4.2 \%$, silt $=7.0 \%$, sand $=88.7 \%$, density $\left(\mathrm{g} / \mathrm{cm}^{3}\right)=2.4$, and a water holding capacity $=70 \%$. The soil was brought to lab, sieved $(5 \mathrm{~mm})$ and air dried prior to experimental procedures.

\subsection{Test chemicals}

The effects of glyphosate and dimethoate on test species were studied using three different concentrations, ranging from the field dose (FD), i.e. the recommended application rate, to 10 times the FD of the commercial formulation of glyphosate (Roundup Ultra $\AA$ with $360 \mathrm{~g} \mathrm{Al} / \mathrm{L}$ ) which contains glyphosate-isopropylammonium (45\%), surfactant (16\%) and water $(42.5 \%)$, and the organophosphorous insecticide dimethoate (AGROR ${ }^{\mathbb{B}}$, with $400 \mathrm{~g} \mathrm{AI} / \mathrm{L}$ ) which contains dimethoate $(40 \%)$, ciclohexanone $(28.4 \%)$, nonylphenol ethoxylate $(2.2 \%)$, petroleum naphta (26.1\%), and calcium alkyl benzene sulfonate inpropil 2-ol $(0.4 \%)$. The commercial formulations were obtained from a local supplier.

More specifically, the nominal concentrations for glyphosate ranged from $1.8 \mathrm{~kg}$ a.i./ha (predicted environmental concentration (PEC) in first $5 \mathrm{~cm}$ of soil according to the FOCUS model (FOCUS, 2007) $\approx 1.7 \mathrm{mg}$ a.i. $/ \mathrm{kg}$ soil), which is the recommended application dose, $9 \mathrm{~kg}$ a.i/ha ( 5 fold the recommended dose) to $18 \mathrm{~kg}$ a.i/ha of glyphosate ( 10 fold the recommended dose); for dimethoate ranged from $0.4 \mathrm{~kg}$ a.i./ha (predicted environmental concentration (PEC) in first $5 \mathrm{~cm}$ of soil according to the FOCUS model $\approx 0.3 \mathrm{mg} / \mathrm{kg}$ soil), which is the recommended application dose, $2 \mathrm{~kg}$ a.i./ha ( 5 fold the recommended dose) to $4 \mathrm{~kg}$ a.i./ha (10 fold the recommended dose). The binary mixtures were made using the same concentrations of the two pesticides at the field dose, 5 times the field dose and 10 times the field dose in an one fixed ratio design. For each treatment and control, three replicates were made, in a total of 30 microcosms tested. Pesticides were applied at the surface of the soil layer using a common sprayer.

\subsection{Small-scale terrestrial ecosystem (STEM)}

The small-scale terrestrial ecosystems (STEM) consisted of a $2 \mathrm{~mm}$-walled cylindrical PVC pipes (12 cm diameter; $38 \mathrm{~cm}$ deep) with a surface area of $0.113 \mathrm{~m}^{2}$, filled up to $5 \mathrm{~cm}$ from the top with the agricultural soil (Fig. 1). Each STEM was filled with approximately $4 \mathrm{~kg}$ of soil. The bottom of the microcosms was covered with fine plastic gauze $(1.0 \mathrm{~mm}$ aperture) to avoid earthworms from escaping from the microcosms (Fig. 1).

The STEM were placed in an acclimatized moveable cart $(83 \mathrm{~cm}$ length; $55 \mathrm{~cm}$ width; $55 \mathrm{~cm}$ depth) with a hollow lid in order to enclose 5 STEM. Such acclimatized chambers allowed to control soil temperature $\left(12{ }^{\circ} \mathrm{C}\right)$ and humidity within the STEM (Santos et al., 2011a). Six acclimatized chambers, each containing 5 STEM, were used in the experiments.

Each small-scale terrestrial ecosystem (STEM) was incubated at $20 \pm 2{ }^{\circ} \mathrm{C}$, with a 16/8 h light dark regime and an irradiance level of 7000 lux at soil surface of the STEM, for a period of $28 \mathrm{~d}$. Soil water content was adjusted to $70 \%$ of maximum water holding capacity, and was subsequently maintained throughout the experiment by adding sterile water ( $\approx 5 \mathrm{ml}$ every two days) in order to simulate rainfall in normal spring conditions. Ten adult clitellate earthworms and ten turnip seeds were introduced on soil surface of each microcosm. Earthworm weight (as a group) was recorded before their introduction into the microcosms. Five isopods, and 3 alder leaves (broken in small pieces) as food source, were added to each STEM at the beginning of the test. Three bait-lamina strips were also enclosed in the soil of each STEM. After $7 \mathrm{~d}$ of exposure the baits were removed from the soil and the number of empty holes (counted as eaten) was recorded. At the end of $28 \mathrm{~d}$ exposure period the fresh weight and shoot length of $B$. rapa were measured as well as the fresh weight and depth distribution of $E$. andrei along the microcosms. Since the $28 \mathrm{~d}$ of exposure was not sufficient to observe effects on endpoints such as isopod growth and/or reproduction, the survival rate of $P$. pruinosus and four biomarkers of exposure were chosen as endpoints. The animals were kept at $-80^{\circ} \mathrm{C}$ until the enzymatic analyses were performed.

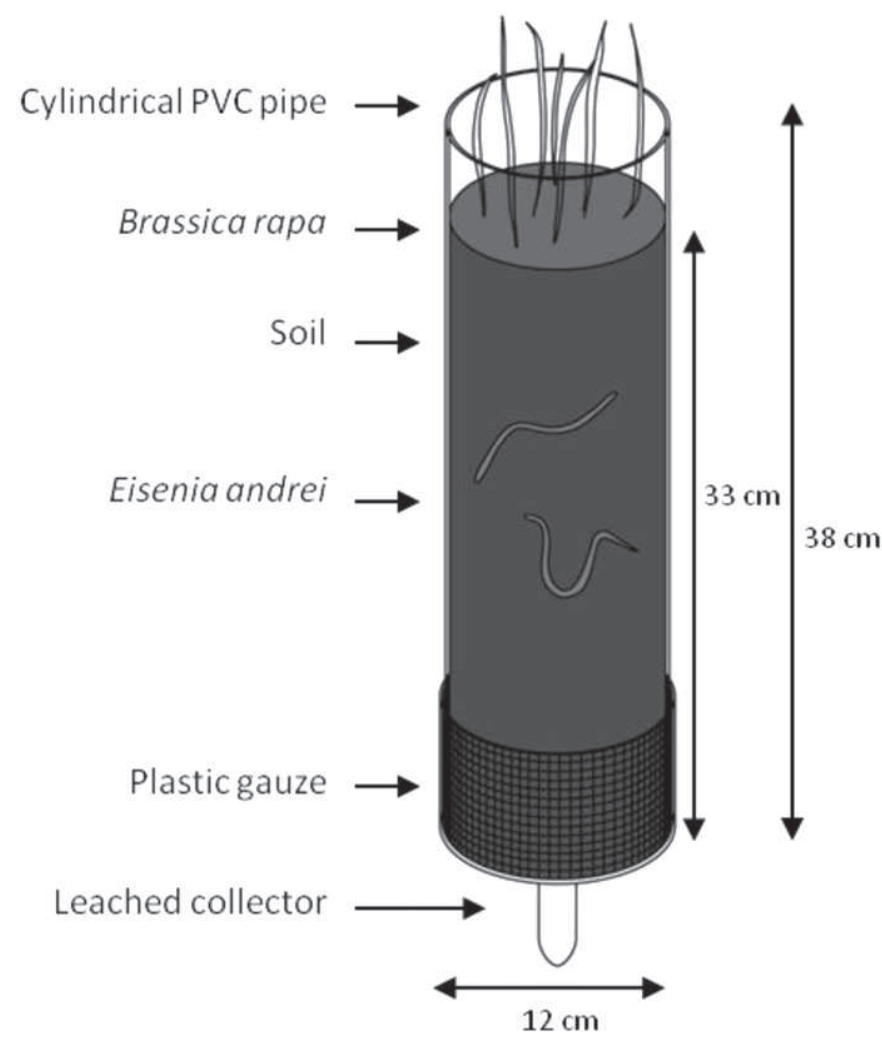

Fig. 1. Small-scale terrestrial ecosystem (STEM) used in the experimental procedure. 


\subsection{Isopods-biomarker evaluation}

Isopods were divided in two sections: head and body. The head was used for the AChE assay and the remaining body was used for GST, CAT, and LPO assays. Homogenization of the animals was made using a sonicator (KIKA Labortechnik U2005 Control ${ }^{\mathrm{TM}}$ ), for approximately $5 \mathrm{~s}$, using $100 \%$ amplitude, with one pulse.

One isopod head per each animal sampled was homogenized using a sonicator in $500 \mu \mathrm{l}$ of potassium phosphate buffer $(0.1 \mathrm{M}, \mathrm{pH} 7.2)$, and the supernatants obtained after centrifugation of the homogenates $\left(4{ }^{\circ} \mathrm{C}, 3800 \mathrm{~g}\right.$, and $\left.3 \mathrm{~min}\right)$ were removed and stored at $-80{ }^{\circ} \mathrm{C}$ until enzymatic analysis. The AChE activity determination was performed according to the Ellman method (Ellman et al, 1961) adapted to microplate (Guilhermino et al., 1996) as follows. In a 96 well microplate $250 \mu \mathrm{l}$ of the reaction solution was added to $50 \mu \mathrm{l}$ of the sample and the absorbance was read at $414 \mathrm{~nm}$, after 10,15, and $20 \mathrm{~min}$. The reaction solution had $1 \mathrm{ml}$ of 5.50-dithiobis-2-nitrobenzoic acid (DTNB) $10 \mathrm{mM}$ solution, $1.280 \mathrm{~m}$ of $0.075 \mathrm{M}$ acetylthiocholine iodide solution and $28.920 \mathrm{ml}$ of $0.1 \mathrm{M}$ phosphate buffer. The enzymatic activity is expressed as unit (U) per mg of protein. A U corresponds to one nmol of substrate hydrolyzed per minute, using a mola extinction coefficient of $1.36 \times 10^{-3} \mathrm{M}^{-1} \mathrm{~cm}^{-1}$

Glutathione S-transferases (GST) activity was determined based on the method described by Habig et al. (1974). After sonication, $100 \mu \mathrm{l}$ of the post-mitochondria supernatant PMS was mixed to $200 \mu \mathrm{l}$ of a reaction solution. The reaction solution was a mixture of $4.95 \mathrm{ml} \mathrm{K-phosphate} \mathrm{buffer} 0.1 \mathrm{M} \mathrm{(pH} \mathrm{6.5)} \mathrm{with} 900 \mu \mathrm{l}$ L-glutathione reduced (GSH) $10 \mathrm{mM}$, and $150 \mu \mathrm{l}$ 1-chloro-2.4-dinitrobenzene (CDNB) $10 \mathrm{mM}$ and it was measured at $340 \mathrm{~nm}$. The enzymatic activity is expressed as unit $(U)$ per $\mathrm{mg}$ of protein. A $U$ corresponds to one nmol of substrate hydrolyzed per minute, using a molar extinction coefficient of $9.6 \times 10^{-3} \mathrm{M}^{-1} \mathrm{~cm}^{-1}$.

Catalase (CAT) activity was determined based on the method described by Clairborne (1985). We mixed $15 \mu \mathrm{l}$ of PMS with $150 \mu \mathrm{l} \mathrm{H}_{2} \mathrm{O}_{2} 0.030 \mathrm{M}$, and $135 \mu \mathrm{l}$ K-phosphate $0.05 \mathrm{M}$ ( $\mathrm{pH} 7.0$ ) and measured the decomposition of the substrate $\left(\mathrm{H}_{2} \mathrm{O}_{2}\right)$ at $240 \mathrm{~nm}$. The enzymatic activity is expressed as unit $(U)$ per $\mathrm{mg}$ of protein. A $U$ corresponds to one $\mu \mathrm{mol}$ of substrate hydrolyzed per minute, using a molar extinction coefficient of $40 \mathrm{M}^{-1} \mathrm{~cm}^{-1}$. Ten replicates were used for each processing methodology for this enzymatic biomarker.

The Lipid peroxidation (LPO) assay was based on the methods described by (Bird and Draper, 1984) and (Ohkawa et al., 1979) by measuring thiobarbituric acidreactive substances (TBARS) at $535 \mathrm{~nm}$. The reaction included a mixture of $150 \mu \mathrm{L}$ homogenated tissue, $500 \mu \mathrm{L}$ trichloroacetic acid sodium salt (TCA) $12 \%(\mathrm{w} / \mathrm{v}), 500 \mu \mathrm{L}$ 2-thiobarbituric acid (TBA) $0.73 \%(\mathrm{w} / \mathrm{v})$, and $400 \mu \mathrm{L}$ Tris- $\mathrm{HCl} 60 \mathrm{mM}$ with diethylenetriaminepentaacetic acid (DTPA) $0.1 \mathrm{mM}$. The reaction mixture was then incubated at $100{ }^{\circ} \mathrm{C}$ in a water bath for $1 \mathrm{~h}$. After this, samples were centrifuged for $5 \mathrm{~min}$ at $11,500 \mathrm{rpm}\left(25^{\circ} \mathrm{C}\right)$. Samples were kept away from light, at $25^{\circ} \mathrm{C}$ and immediately read at $535 \mathrm{~nm}$. LPO is expressed as nmol TBARS hydrolyzed per minute per mg of wet weight, using a molar extinction coefficient of $1.56 \times 10 \mathrm{M}^{-1} \mathrm{~cm}^{-1}$.

\subsection{Bait-lamina method}

Each bait-lamina consisted on a plastic strip with 16 holes filled with a mixture of cellulose, oat-bran, and active charcoal (70:27:3) and buried vertically in the soil of each STEM. After the exposure period of $7 \mathrm{~d}$ the baits are removed from the STEM and washed with tap water, the number of eaten baits (light fall through the bait) and non-eaten baits (light does not fall through the baits) was recorded (Kratz, 1998)

\subsection{Chemical analysis}

Soil chemical analysis was performed after $28 \mathrm{~d}$ of exposure. Soil samples from the upper soil layer $(0-10 \mathrm{~cm})$ and the lower soil layer $(10-20 \mathrm{~cm})$ were taken and sent for chemical analysis at Marchwood Scientific Services, Southampton, UK. The following method was used for the analysis of soil samples containing glyphosate and dimethoate: samples were first air dried and ground, after which a 1-2 g was used for pesticide extraction with acidified acetonitrile. This subsample was then filtered and the filtrate subjected to further analysis by Liquid Chromatographytandem Mass Spectrometry following a pre-treatment buffering stage. The instrument used for the analysis was an Agilent 6410 Triple quad LCMS-MS. Standards were prepared in solvents at 7 levels with recoveries between $80 \%$ and $120 \%$ (Santos et al., 2011a).

\subsection{Statistical analysis}

Differences in plants' fresh weight and length, earthworm's fresh weight and number of holes eaten in the bait-lamina strips in the microcosms where pesticide was applied were compared with control microcosms using an one-way ANOVA followed by a post-hoc Dunnett's test. Since the enzymatic data provided by the biomarkers evaluation were not normally distributed and data transformation did not correct for normality, a Kruskal-Wallis ANOVA on Ranks was performed, followed by the Dunnett's method when significant differences were found. The concentration after which $50 \%$ of the animals were found dead $\left(\mathrm{LC}_{50}\right)$ was calculated using the logistic equation

Survival $=c \times e^{((\log ((c-c \times 0.5-b \times 0.5) / c) \times(\text { dimethoate } / a))+b}$

where $c$ is the control response, $b$ is a scale parameter (estimated between 1 and 4), $a$ is estimated $\mathrm{LC}_{50}$ value and dimethoate is dimethoate exposure concentration.

The $\mathrm{DT}_{50}$ after $28 \mathrm{~d}$ of exposure of each pesticide in soil was calculated using the following equation:

$\mathrm{PEC} t=$ initial PEC $\times e^{(-k t)}$

where PEC at time $t$ was the pesticide concentration after $28 \mathrm{~d}$ of exposure $(\mathrm{mg} / \mathrm{kg})$, the initial PEC was the pesticide concentration at day 0 of exposure, $k$ was the dissipation rate constant, which is equal to $0.693 / \mathrm{DT}_{50}$, and $t$ was the time of exposure (FOCUS, 2007).

The Independent Action (IA) model can be used for the comparison of the observed data and the predicted toxicity (probabilities of effect), taking into account the single exposure results of each pesticide (Jonker et al., 2005). According to this reference model the probability of effect of a given organism to one compound is independent from the probability of the effect of the same organism being exposed to a second compound, meaning that the resultant mixture toxicity can be predicted based on probability statistics (Köneman and Pieters, 1996). For quantal responses, which can have only two possible outcomes 0 or 1 (i.e. escape response of the earthworms), the unaffected proportion can be expressed by the probabilities of nonresponse to the toxicants, according to the following equation:

Mixture toxicity $\left(q_{1}, \ldots, q_{n}\right)=\prod_{i-1}^{n} q i(c i)$

where $q_{i}\left(c_{i}\right)$ is the probability of nonresponse at concentration $c$ of toxicant $i$ (Martin et al., 2009). This equation can be converted to represent continuous data (i.e. shoot length and fresh weight of $B$. rapa), by multiplying it by the maximum value (represented by max), which is the control, according to the following equation

Mixture toxicity $\left(q_{1}, \ldots, q_{n}\right)=\max \prod_{i-1}^{n} q i(c i)$

\section{Results and discussion}

\subsection{Chemical analysis}

The results showed that pesticide concentration in the $0-10 \mathrm{~cm}$ layer was always higher than the layer of $10-20 \mathrm{~cm}$ (Table 1). This was expected, since the application of the pesticide was made at the soil surface, and during the experiment the addition of water could have contributed to a further dissipation of the pesticide along the test period.

Glyphosate is considered moderately persistent in soil, with a half-life of between 1.1 and 13 d (EFSA, 2006), and dimethoate is also moderately persistent in the soil, with a half-life of $4-16 \mathrm{~d}$ (Wauchope et al., 1992). According to the analysis, after the $28 \mathrm{~d}$ of exposure, in both soil layers, only small amount of pesticide

\section{Table 1}

Chemical analysis of pesticide residues in soil from the upper layer $(0-10 \mathrm{~cm})$ and lower layer $(10-20 \mathrm{~cm})$ of the STEM after $28 \mathrm{~d}$ of exposure. $\mathrm{G}$ is for glyphosate, D is for dimethoate. FD is for field dose. ND is for not detected. All units are in $\mathrm{mg}$ a.i. $/ \mathrm{kg}$ soil.

\begin{tabular}{|c|c|c|c|c|}
\hline $\begin{array}{l}\text { Nominal } \\
\text { concentration } \\
\text { (mg a.i./kg) }\end{array}$ & $\begin{array}{l}\text { Glyphosate } \\
(0-10 \mathrm{~cm})\end{array}$ & $\begin{array}{l}\text { Glyphosate } \\
(10-20 \mathrm{~cm})\end{array}$ & $\begin{array}{l}\text { Dimethoate } \\
(0-10 \mathrm{~cm})\end{array}$ & $\begin{array}{l}\text { Dimethoate } \\
(10-20 \mathrm{~cm})\end{array}$ \\
\hline 1.7 (field dose) & 0.12 & $<0.005$ & - & - \\
\hline $8.5(5 \times \mathrm{FD})$ & 2.13 & $<0.005$ & - & - \\
\hline $17(10 \times \mathrm{FD})$ & 0.91 & 0.25 & - & - \\
\hline 0.3 (field dose) & - & - & $<0.01$ & $<0.01$ \\
\hline $1.5(5 \times \mathrm{FD})$ & - & - & 0.02 & $<0.01$ \\
\hline $3(10 \times \mathrm{FD})$ & - & - & 0.04 & $<0.01$ \\
\hline $\begin{array}{l}\text { Mix } 1 \times \text { FD }(1.7 \\
\text { G }+0.3 \mathrm{D})\end{array}$ & ND & $<0.005$ & 0.02 & $<0.01$ \\
\hline $\begin{array}{l}\text { Mix } 5 \times \text { FD }(8.5 \\
\text { G }+1.5 \mathrm{D})\end{array}$ & 0.36 & $<0.005$ & 0.04 & $<0.01$ \\
\hline $\begin{array}{l}\text { Mix } 10 \times \text { FD }(17 \\
\text { G }+1.5 \mathrm{D})\end{array}$ & 2.41 & $<0.005$ & 0.07 & $<0.01$ \\
\hline
\end{tabular}


Table 2

Observed values (mean net response and 95\% confidence limits). The endpoint measured for the earthworm Eisenia andrei was the proportion of worms in the soil lower layer (10-20 cm); for Brassica rapa were the shoot length (in $\mathrm{cm} /$ plant), fresh weight (in $\mathrm{mg} /$ plant), and the germination success (number of plants per STEM); for baitlamina was the consumption of baits (number of baits). G: glyphosate, $D$ : dimethoate. All units of the treatments (nominal concentrations) are in mg a.i./kg soil.

\begin{tabular}{|c|c|c|c|c|c|c|}
\hline $\begin{array}{l}\text { Treatment (nominal } \\
\text { concentration) }\end{array}$ & $\begin{array}{l}\text { Eisenia andrei } \\
\text { (proportion in } \\
10-20 \mathrm{~cm} \text { ) }\end{array}$ & $\begin{array}{l}\text { Eisenia andrei } \\
\text { (weight variation) }\end{array}$ & $\begin{array}{l}\text { Brassica rapa } \\
\text { (fresh weight) }\end{array}$ & $\begin{array}{l}\text { Brassica rapa } \\
\text { (shoot length) }\end{array}$ & $\begin{array}{l}\text { Brassica rapa } \\
\text { (germination success) }\end{array}$ & $\begin{array}{l}\text { Bait-lamina (number } \\
\text { of baits eaten) }\end{array}$ \\
\hline Control & $20(4-36)$ & $34(8-60)$ & $191(156-225)$ & $11.1(10.3-12)$ & $7.3(6.5-8.2)$ & $32(27-37)$ \\
\hline $1.7 \mathrm{G}$ & $21(14-26)$ & $22(16-27)$ & $84(73-95)$ & $7.4(6.4-8.4)$ & $8.6(6.6-10.7)$ & $40(35-45)$ \\
\hline $8.5 \mathrm{G}$ & $10(-0.1-30)$ & $11(8-14)$ & $53(23-82)^{*}$ & $6.9(4.5-9.4)$ & $1.7(1.5-1.8)^{*}$ & $37(24-50)$ \\
\hline $17 \mathrm{G}$ & $23(17-30)$ & $25(20-30)$ & $57(56-58)$ & $2.4(1.4-3.5)$ & $1(0.7-1.3)^{*}$ & $35(22-49)$ \\
\hline $0.3 \mathrm{D}$ & $20(-3-43)$ & $27(10-43)$ & $216(122-310)$ & $12.7(11.7-13.7)$ & $8.9(6.6-11.4)$ & $22(16-29)$ \\
\hline $1.5 \mathrm{D}$ & $30(0.1-60)$ & $25(2-49)$ & $205(42-294)$ & $11.1(10.3-12)$ & $8.3(4.6-12)$ & $17(13-21)$ \\
\hline $3 \mathrm{D}$ & $37(11-62)$ & $0.4(0.2-0.6)$ & $143(101-184)$ & $12.5(11.4-13.5)$ & $8.9(7.6-10.3)$ & $3(2-3)^{*}$ \\
\hline $\operatorname{Mix} 1(1.7 \mathrm{G}+0.3 \mathrm{D})$ & $30(19-41)$ & $26(4-47)$ & $136(107-164)$ & $8.5(7.4-9.5)$ & $5.9(4.4-7.7)$ & $11(10-12)^{*}$ \\
\hline $\operatorname{Mix} 5(8.5 \mathrm{G}+1.5 \mathrm{D})$ & $10(-1-30)$ & $7(1-14)$ & $45(37-52)^{*}$ & $4.4(3.4-4.4)^{*}$ & $5.6(4.6-6.6)$ & $9(5-12)^{*}$ \\
\hline $\operatorname{Mix} 10(17 G+3 D)$ & $33(27-40)$ & -3 & $23(23-24)^{*}$ & $4(3.5-4.5)^{*}$ & $5.3(3.6-7.0)$ & $5(4-7)^{*}$ \\
\hline
\end{tabular}

* Indicates statistical differences (Dunnett's test, $p<0.05$ ).

residues was retrieved (Table 1 ). The $\mathrm{DT}_{50}$ for glyphosate was $7.7 \mathrm{~d}$ and for dimethoate was $5.8 \mathrm{~d}$. Thus there was a rapid dissipation observed for both pesticides which was in accordance with the data concerning the half-life of these pesticides in soil.

\subsection{B. rapa}

Regarding the exposure to glyphosate, statistical differences on the fresh weight, shoot length, and the number of plants that germinated after the $28 \mathrm{~d}$ of exposure (germination success) of $B$. rapa were observed only at concentrations higher than the recommended field dose (Table 2). The number of plants that germinated after the $28 \mathrm{~d}$ of exposure (germination success) was significantly lower in the concentration made with 5 and 10 times the field dose. After exposure to the insecticide dimethoate, no differences on the endpoints were observed (Table 2). The effects of the binary mixtures on the shoot length and fresh weight of the plants were observed at concentrations 5 and 10 times higher than the field dose of both pesticides but no effects in the germination success were observed (Table 2 ).

The recommended application rate of both pesticides did not affect $B$. rapa. This result was in accordance with a previous study from the same authors where the herbicide glyphosate did not affect B. rapa grown for $21 \mathrm{~d}$ on soil LUFA 2.2 (Santos et al., 2011b). A previous study where the recommended dose of dimethoate was applied using the same STEM did not cause impairment in growth of this plant species (Santos et al., 2011a).

The observed and predicted values were compared using a Student $t$-test, and no significant differences were observed, although the regression equations derived from the data were different from the additivity line $(Y=1)$, thus both pesticides did not act additively in the tested system. The predicted values for fresh weight and shoot length at the field dose were similar to the observed values, which could be an indication that these pesticides, at the recommended application rate, behave according to the reference model of IA (Figs. 2 and 3). There was a discrepancy between the observed values for the germination success and the predicted values indicating that the number of plants that germinated was lower than expected (Fig. 4). However, the observed germination success of the mixture made with the field dose (6 plants per STEM) was similar to the values observed on the control (7.3 plants per STEM). Thus the synergistic prediction was due to the fact that the germination success at the field dose of glyphosate (8.7 plants per STEM) and dimethoate (9.0 plants per STEM) was higher than the control. The predicted result for the mixture was a full germination (10. 4 plants per STEM), hence this synergistic deviation should be discussed taking in

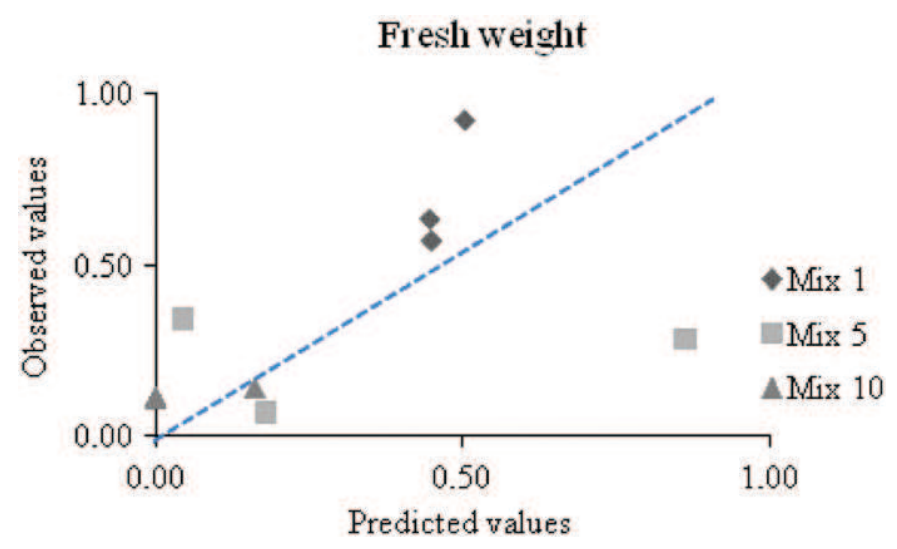

Fig. 2. Predicted and observed values (as percentage of control) of fresh weight of Brassica rapa after exposure to the binary mixtures of glyphosate and dimethoate in the STEM for $28 \mathrm{~d}$. The dashed line $(Y=1)$ represents additivity according to the reference model of Independent Action.

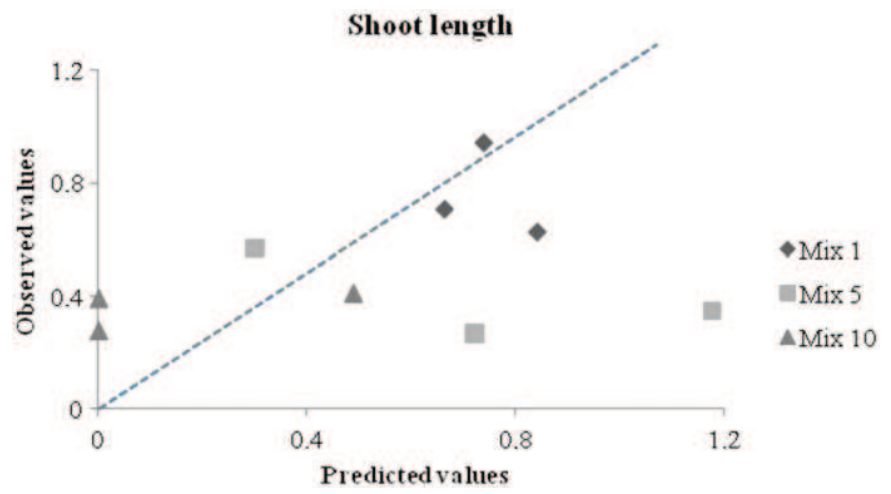

Fig. 3. Predicted and observed values (as percentage of control) of shoot length of Brassica rapa after exposure to the binary mixtures of glyphosate and dimethoate in the STEM for $28 \mathrm{~d}$. The dashed line $(Y=1)$ represents additivity according to the reference model of Independent Action.

consideration the difference between observed and predicted values (with a difference of 4 plants per STEM) or taking in consideration the difference between the observed values of the mixture and the control (difference of 1 plant per STEM). In a previous experiment using the same STEM to evaluate the effects of dimethoate on spirodiclofen, the average number of plants in the control was also 7.3 (Santos et al., 2011a), thus the synergism observed could be considered of low concern in what relates to the germination success of this species. 


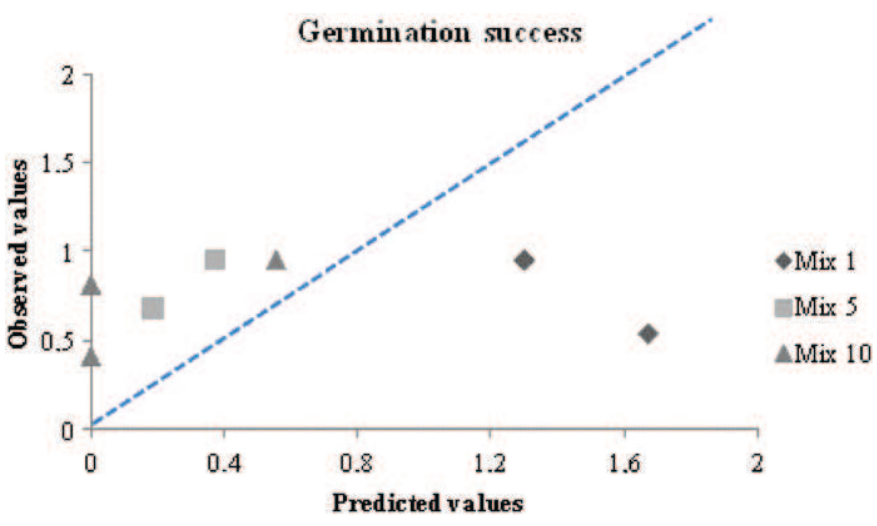

Fig. 4. Predicted and observed values (as percentage of control) of germination success of Brassica rapa after exposure to the binary mixtures of glyphosate and dimethoate in the STEM for $28 \mathrm{~d}$. The dashed line $(Y=1)$ represents additivity according to the reference model of Independent Action.

The effect of the mixture made with 5 and 10 times the field dose was synergistic for fresh weight (with differences in observed and predicted values higher than 2.5) and slightly synergistic for the shoot length, but the mixture effect was antagonistic on the germination success, since more plants germinated than it was expected (Figs. 2-4). The synergism observed should be analyzed taking into account the biological meaning of a higher decrease in the shoot length and fresh weight of the plants than it was expected. This decrease was not very steep, and the predicted values were close to the confidence interval of the observed values, thus it this departure from additivity should be interpreted carefully in terms of stating an impact of the combined pesticides on these two endpoints. The germination success was less affected than the length and fresh weight, but this could be due to the fact that no plants germinated in 2 out of the 3 STEM with 10 times the field dose of glyphosate. The impact on the germination success seems to be driven by the amount of glyphosate on the mixture, thus a possible explanation for a smaller effect than predicted could be the interaction between the two pesticides in the STEM, leading to a smaller toxicity than the individual exposure to the herbicide.

The choice of endpoint (shoot length or fresh weight and germination success) led to different deviations from the reference model. This could be due to the fact that the shoot length and fresh weight are endpoints closely correlated, if the shoot length is affected the weight of the plant should also be affected, thus smaller plants have less weight and vice-versa. The germination success cannot be compared directly with the other two endpoints, since the number of seeds that germinated into full grown plants is independent of the length and weight that these plants could have. For instance just 3 plants germinated in the exposure to 10 times the field dose of glyphosate, but their weight and length did not differ statistically from the control (Table 2). The opposite occurred in the binary mixtures made with 5 and 10 times the field dose, where differences on length and weight were observed although no differences on germination success were observed (Figs. 2-4). Same conclusions have been derived from other toxicity studies (Cedergreen and Streibig, 2005), where the choice of endpoint (fresh weight or number of leaves per plant) led to different and contradictory results in term of deviations from the mixture toxicity model according to the endpoint chosen.

\subsection{E. andrei}

There was a decrease in the earthworm's weight in all concentrations tested, although no statistical differences were observed in any of the treatments made (Table 2). The absence of effects in earthworm's weight after a single application of the recommended doses of glyphosate (Dalby et al., 1995) and dimethoate using the same STEM (Santos et al., 2011a) (Fig. 5).

The observed and predicted values were compared using a Student $t$-test, and no significant differences were observed, although the regression equation derived from the data was different from the additivity line $(Y=1)$, thus both pesticides did not act additively in the tested system. The predicted values were similar to the observed values, and in the majority of the mixtures the effects were smaller than the prediction based on the individual responses (Fig. 6). There was not a consistent pattern in terms of weight loss, maybe because the variation within the replicates was high and the time of exposure and concentrations tested were not enough to derive a dose-response effect.

No differences were observed regarding the depth distribution, in any of the treatments (Table 2), although there seems to be an increase in weight loss with increasing concentrations of the insecticide dimethoate in both single and binary exposure. Regarding the distribution of earthworms (depth distribution) in the control, $80 \%$ of the worms were found in the upper layer $(0-10 \mathrm{~cm})$ of the soil column (Table 2 ) as expected by this species ecology (Langdon et al., 2005). The same occurred following the application of the two pesticides in single and binary exposures (Table 2). The absence effects on the depth distribution of the earthworms following the application of the recommended doses of glyphosate-based herbicide to the earthworm Eisenia fetida was observed in a previous study (Verrel and Van Buskir, 2004). In a

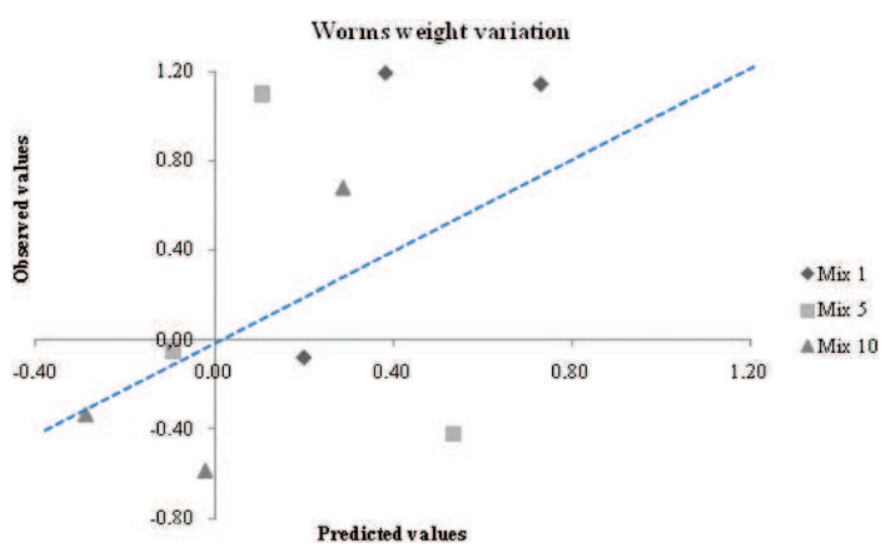

Fig. 5. Predicted and observed values (as percentage of control) of weight variation of Eisenia andrei after exposure to the binary mixtures of glyphosate and dimethoate in the STEM for $28 \mathrm{~d}$. The dashed line $(Y=1)$ represents additivity according to the reference model of Independent Action.

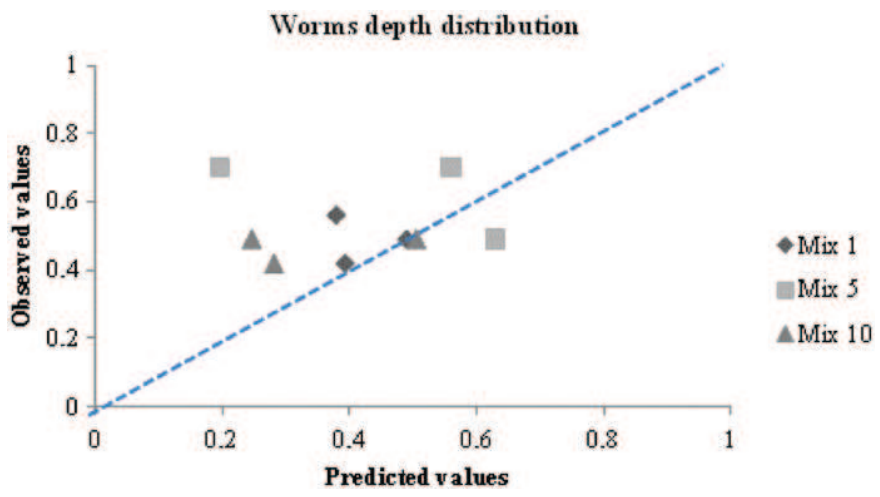

Fig. 6. Predicted and observed values (as percentage of control) of depth distribution of Eisenia andrei after exposure to the binary mixtures of glyphosate and dimethoate in the STEM for $28 \mathrm{~d}$. The dashed line $(Y=1)$ represents additivity according to the reference model of Independent Action. 


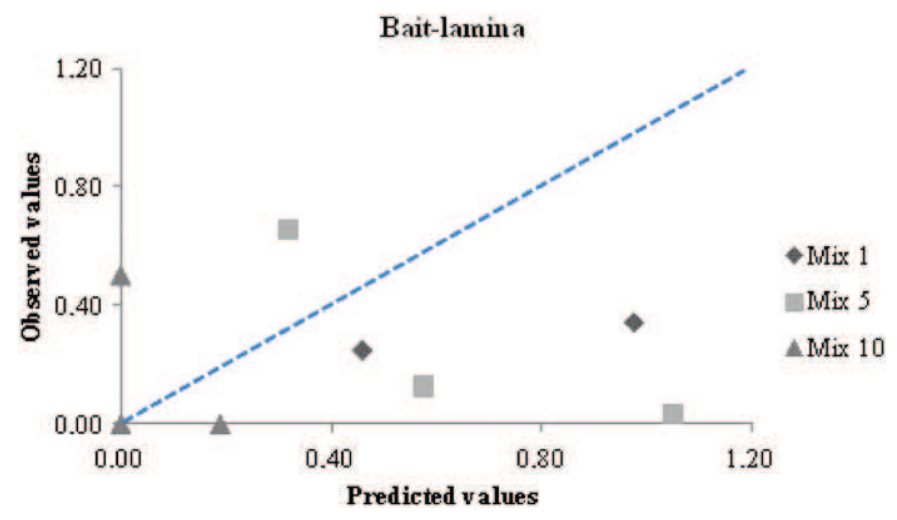

Fig. 7. Predicted and observed values (as percentage of control) of number of baitlamina eaten after exposure to the binary mixtures of glyphosate and dimethoate in the STEM for $28 \mathrm{~d}$. The dashed line $(Y=1)$ represents additivity according to the reference model of Independent Action.

previous study the depth distribution of the earthworms after application of dimethoate using the same STEM, led to an increase of the earthworms on the upper layer of the soil column to the exerted toxic effect of this insecticide (Santos et al., 2011a). The earthworms retrieved in the cited study presented several constrictions on the body and did not react when poked, but in the present study those conditions were not observed in any of the earthworms recovered from the STEM. One possible explanation for this difference could be the fact that the worms buried deeper in the soil column immediately after pesticide application or in the subsequent days, and did not suffer the toxic effects observed in the cited study.

The observed and predicted values were compared using a Student $t$-test, and no significant differences were observed, although the regression equation derived from the data was different from the additivity line $(Y=1)$, thus both pesticides did not act additively in the tested system. Again, the predicted values were similar to the observed values, and in most mixtures the effects were smaller than the prediction based on the individual responses (Fig. 7).

\subsection{Bait-lamina strips}

After exposure to the herbicide glyphosate the number of empty holes (counted as eaten) was higher than the control (Table 2). Thus, glyphosate seemed to have triggered the feeding activity of the soil organisms in the microcosm. The same response was observed in an agricultural field treated with glyphosate where feeding activity (bait-lamina test) increased after exposure to this herbicide (Reinecke et al., 2002). The feeding activity decreased at the field dose of dimethoate and after exposure to 5 and 10 times the field dose, with statistical difference in the highest concentration of dimethoate (Table 2); the application of recommended doses of the organophosphorous pesticide chlorpyrifos in a field experiment also conveyed a significant lower consumption of the baits buried in the treated plots after a period of $50 \mathrm{~d}$ of exposure (Casable et al., 2007). In the joint toxicity evaluation, a statistically significant decrease in bait-lamina consumption was observed in all the three binary mixtures performed in comparison with the control (Table 2).

The observed and predicted values were compared using a Student t-test, and no significant differences were observed, although the regression equation derived from the data was different from the additivity line $(Y=1)$, thus both pesticides did not act additively in the tested system. The difference between the predicted and observed values in the mixtures with the field and 5 times the field dose indicated that the mixture was synergistic, with observed effects, respectively, 2.6 and 12.9 times smaller than the predicted effects (Fig. 7). In this case, apparently, the synergism in the toxic effect of the mixture was driven by the insecticide dimethoate, since this pesticide was also the responsible for a great reduction on single exposure treatments. In the mixture made with 10 times the field dose, the effects were smaller than the individual exposure to dimethoate, thus the synergistic effects did not follow an increase in concentration of the mixture. As it was stated previously, this could be due to the fact that the single exposure to the insecticide dimethoate at 10 times the field dose had such a great impact on the number of baits eaten that on the binary mixture the effects could not be enhanced, and thus the synergism ceased to be consistent with increasing concentrations of dimethoate.

Bait-lamina consumption has been linked to the amount of soil organisms biomass, and a strong correlation between lower bait consumption and contaminated sites and has been established (Kools et al., 2009). Furthermore, a link between the number of bait-lamina eaten and the presence of earthworms in soil has been demonstrated in previous studies, thus bait-lamina consumption is in general correlated with the activity of earthworms (Van Gestel et al., 2003). The decrease on E. andrei weight in the STEM with dimethoate applied at 5 and 10 times the field dose could explain the decrease on the number of baits eaten. The baitlamina proven to be a good indicator of the biological activity of the soil fauna in this designed microcosm experiment. Given that this method is used to assess a functional endpoint (feeding activity), the decreased feeding activity with the increase of dimethoate concentration could be regarded as impairment in soil function (Kula and Römbke, 1998; Filzek et al., 2004).

\subsection{P. pruinosus}

The application of glyphosate did not affect the number of isopods found after the $28 \mathrm{~d}$ of exposure; the survival rate was very similar to the one observed in control STEM (Table 3). However, exposure to dimethoate affected the number of isopods that survived the exposure period, even at the field dose, less than half of the isopods added in the beginning of the tests were retrieved. Exposure to 5 and 10 times the field dose of dimethoate and the binary mixtures made with the same two concentrations led to a significant decrease in the number of animals that survived the exposure (Table 3 ).

The effects of the insecticide dimethoate on the retrieval rate of the isopod P. pruinosus $\left(\mathrm{EC}_{50}=0.46(0.16-0.80) \mathrm{mg} / \mathrm{kg}\right)$ was much lower than the concentration responsible for reducing $50 \%$ the survival rate $\left(\mathrm{LC}_{50}\right.$ higher than $75 \mathrm{mg} / \mathrm{kg}$ ) of the isopod species Porcellio scaber (Fischer et al., 1997), and the species Porcellio dilatatus ( $\mathrm{LC}_{50}$ higher than $20 \mathrm{mg} / \mathrm{kg}$ ) exposed for $10 \mathrm{~d}$ on a siltloam soil on a microcosm experiment (Engenheiro et al., 2005). The reason for the discrepancy between the values found in the present study and the works cited above could be the method of pesticide application in the STEM. Since the pesticides were applied using a sprayer after the isopods were in the microcosm, the animals were immediately exposed to the pesticide, which can be considered a more direct and extra route of exposure of dimethoate to the isopods (Sousa et al., 2000; Loureiro et al., 2002).

The assessment of the four biomarkers led to statistically significant differences only on the AChE activity after exposure to dimethoate at field dose and binary mixture and on LPO activity at the field dose of both pesticides and binary mixture (Table 3). GST activity in the treatments was close to the basal levels observed in control animal, and this detoxifying enzyme does not seem to be triggered by the two pesticides, which has been recorded in previous studies (Jemec et al., 2010). CAT is involved in the reduction of reactive oxygen species (ROS), and its levels decreased around $66 \%$ and $45 \%$ in glyphosate and 
Table 3

Observed values (mean net response and standard error). The endpoints measured for the isopod Porcellionides pruinosus were the survival rate (\% of animals alive per STEM) and the Acetylcholinesterase (AChE), Glutathione-S-transferase (GST), Catalase (CAT), and Lipid peroxidation (LPO) activity levels. G: glyphosate, D: dimethoate, and $\mathrm{ND}$ : not determined. All units of the treatments (nominal concentrations) are in $\mathrm{mg}$ a.i./.kg soil.

\begin{tabular}{|c|c|c|c|c|c|}
\hline $\begin{array}{l}\text { Treatment } \\
\text { (nominal concentration) }\end{array}$ & $\begin{array}{l}\text { Porcellionides } \\
\text { pruinosus (\% survival) }\end{array}$ & $\begin{array}{l}\text { Porcellionides } \\
\text { pruinosus (AChE) }\end{array}$ & $\begin{array}{l}\text { Porcellionides } \\
\text { pruinosus (GST) }\end{array}$ & $\begin{array}{l}\text { Porcellionides } \\
\text { pruinosus (CAT) }\end{array}$ & $\begin{array}{l}\text { Porcellionides } \\
\text { pruinosus (LPO) }\end{array}$ \\
\hline Control & 87 & $73(66-70)$ & $4.2(2-6)$ & $130(119-141)$ & $75(64-86)$ \\
\hline $1.7 \mathrm{G}$ & 60 & $64(61-67)$ & $1.4(1-2)$ & $126(124-128)$ & $101(98-104)^{*}$ \\
\hline $8.5 \mathrm{G}$ & 87 & $58(56-60)$ & $1.5(1-2)$ & $121(116-125)$ & 97 (95-99) \\
\hline $17 \mathrm{G}$ & 87 & $112(99-124)$ & $2.5(2-3)$ & $121(115-127)$ & $80(77-82)$ \\
\hline $0.3 \mathrm{D}$ & 47 & $42(27-50)^{*}$ & $2.5(2-3)$ & $134(128-140)$ & $105(95-115)^{*}$ \\
\hline $1.5 \mathrm{D}$ & $7^{*}$ & ND & ND & ND & ND \\
\hline 3 D & $0^{*}$ & ND & ND & ND & ND \\
\hline $\operatorname{Mix} 1(1.7 \mathrm{G}+0.3 \mathrm{D})$ & $27^{*}$ & $24(15-34)^{*}$ & $3.7(3-4)$ & $143(134-151)$ & $126(106-146)^{*}$ \\
\hline $\operatorname{Mix} 5(8.5 \mathrm{G}+1.5 \mathrm{D})$ & $13^{*}$ & ND & ND & ND & ND \\
\hline $\operatorname{Mix} 10(17 G+3 D)$ & $0^{*}$ & ND & ND & ND & ND \\
\hline
\end{tabular}

* Indicates statistical differences (Dunnett's test, $p<0.05$ ).

dimethoate field dose, respectively, although no statistical differences were observed. LPO was induced, with statistical differences, at glyphosate and dimethoate field dose concentrations and in the binary mixture. It is known that ROS induces oxidative stress, which could lead to Lipid peroxidation (Valant et al., 2009), thus the inhibition in CAT enzymatic levels can be linked with the increase in LPO levels.

Acetylcholinesterase is responsible for breaking down acetylcholine, and is inhibited by organophosphorous pesticides, since these pesticides bind to the hydroxyl group of the functional part of this enzyme, resulting in an enzyme that has no activity, and ceases to be able to hydrolyze the substrate acetylcholine (Ferreira et al., 2010). AChE inhibition due to exposure to the insecticide dimethoate has been observed in previous studies using terrestrial isopods at sub-lethal concentrations (Engenheiro et al., 2005). This enzyme sensitivity to sub-lethal concentrations of organophosphorous pesticides could indicate impairment of the activity of these soil organisms in soil processes (Loureiro et al., 2005b). The inhibition observed in the AChE activity when dimethoate was present in the soil could be associated with the subsequent mortality rate observed in the isopods; since it has been appointed that a reduction in cholinesterase activity up to $50 \%$ indicated impairment in the survival capacity of the organisms (Ludke et al., 1974).

\subsection{Integration of effects upon exposures in STEM}

Several species were enclosed in the STEM, so an integrative explanation of the effects observed might be useful to fulfill the goals of the present work. As expected, due to the a priori knowledge of pesticides mode of action, effects on plants were mainly driven by the herbicide glyphosate and effects on invertebrates and bait-lamina were mainly driven by the insecticide dimethoate. Some endpoints were clearly more sensitive than others, for instance isopods' survival rate was very affected at concentrations of dimethoate that did not affect weight variation or depth distribution of earthworms. This could be related with the mode of application of the pesticides in the STEM (sprayed on bare soil), thus isopods were immediately exposed to the pesticide whereas earthworms had the opportunity to distribute themselves along the soil column, avoiding pesticide exposure. Earthworms were distributed mainly on the upper layer, and no visual detrimental effects were observed, but their weight was reduced when exposed to high concentrations of dimethoate in both single and binary exposures. Weight loss could be a plausible explanation for the decrease on the number of baits eaten in the referred exposures. Although in some endpoints no statistical differences were observed with increasing concentrations of the pesticides there was a general decrease on the endpoints evaluated among the several species and bait-lamina, mainly at concentrations above the recommended dose.

The interpretation of the results of microcosm's experiments should be made taking in consideration previous experiments, using the same test conditions, so that a comparison between responses can be made (Lukkari et al., 2006). Results from a previous experiment using the same STEM and binary mixtures of dimethoate and spirodiclofen (Santos et al., 2011a), allowed comparing the effects on plants and earthworms. Results obtained with plants were very similar; hence the application of dimethoate did not affect this plant species. The main difference between the two STEM experiments was on the depth distribution of earthworms, thus in the cited study the application of the acaricide spirodiclofen was responsible for the distribution of the earthworms on the lower layer of the soil column. The use of this artificial microcosm (STEM) allowed observing effects on different endpoints (both structural and functional) and several trophic levels, thus increasing the reliability of the results, considering what happens in agricultural fields to non-target organisms after pesticide application.

\section{Conclusions}

At the field dose, no effects were observed in all the endpoints measures in both B. rapa (shoot length, fresh weight and germination success) E. andrei (depth distribution and weight variation) and P. pruinosus (survival rate), but significant difference on the number of bait-lamina eaten were observed. The binary mixture was synergistic on shoot length and fresh weight of $B$. rapa at 5 times the field dose and antagonistic at 10 times the field dose. The effect of the mixtures on the germination success was synergistic at the field dose (fewer plants germinated than expected), but antagonistic at 5 and 10 times the field dose. The decrease in earthworms weight as well as depth distribution was not statistical different in any treatment. Nevertheless, the decrease in earthworm's weight seemed to be related with the decrease in bait consumption, which was synergistic at the field and 5 times the field dose. There was a high mortality rate observed in the isopods after exposure to dimethoate in the STEM conditions whether in single and binary exposures, clearly demonstrating that an increase in dimethoate concentration led to a decrease on the survival rate of this species. Biomarker changes were observed in AChE when isopods were exposed to dimethoate at field dose and binary mixtures and in LPO when exposed to field doses of the pesticides in single and binary exposure. 


\section{Acknowledgments}

This study was supported by a Ph.D. Grant (SFRH/BD/31562/ 2006) attributed to Miguel J.G. Santos by the Portuguese Science and Technology Foundation (FCT) and by the Project AGROMIX-evaluation of the toxicity of mixtures of chemical compounds in agricultural soils (PTDC/AGR-AAM/68676/2006) funded by FCT.

\section{References}

Bird, R.P., Draper, H.H., 1984. Comparative studies on different methods of malonaldehyde determination. Methods Enzymol. 105, 299-305.

Bliss, C.I., 1939. The toxicity of poisons applied jointly. Ann. Appl. Biol. 26, 585-615.

Casablé, N., Piola, L., Fuchs, J., Oneto, M.L., Pamparato, L., Basack, S., Gimenéz, R., Massaro, R., Papa, J.C., Kuten, E., 2007. Ecotoxicological assessment of the effects of glyphosate and chlorpyrifos in an Argentine soya field. J. Soils Sediments 7 (4), 232-239.

Cedergreen, N., Streibig, J.C., 2005. Can the choice of endpoint lead to contradictory results of mixture-toxicity experiments? Environ. Toxicol. Chem. 24 (7), 1676-1683.

Clairborne, A., 1985. Catalase activity. In: Greenwald, R. (Ed.), Handbook of Methods for Oxygen Radical Research. CRC Press, Boca Raton, Florida, pp. 283-284.

Dalby, P.R., Baker, G.H., Smith, S.E., 1995. Glyphosate, 2,4, DB and dimethoate: effects on earthworms survival and growth. Soil Biol. Biochem. 27 (12), 1661-1662.

Ellman, G.L., Courtney, K.D., Andres, V.J., Featherstone, R., 1961. A new and rapid colorimetric determination of acetylcholinesterase activity. Biochem. Pharmac. 7, 88-95

Edwards, C.A., 2002. Assessing the effects of environmental pollutants on soil organisms, communities, processes and ecosystems. Eur. J. Soil Biol. 38, 225-231.

Edwards, C.A., 2004. The importance of earthworms as key representatives of the soil fauna. In: Edwards, C.A. (Ed.), Earthworm Ecology second ed., pp. 3-31.

EFSA, 2006. Conclusion regarding the peer review of the pesticide risk assessment of the active substance dimethoate. European Food and Safety Agency (EFSA). Scientific Report 84, 1-102.

Engenheiro, E.L., Hankard, P.K., Sousa, J.P., Lemos, M.F., Weeks, J.M., Soares, A.M.V.M., 2005. Influence of dimethoate on acetylcholinesterase activity and locomotor function in terrestrial isopods. Environ. Toxicol. Chem. 24 (3), 603-609.

Ferreira, N.G.C., Santos, M.J.G., Domingues, I., Calhôa, C.F., Monteiro, M., Amorim, M.J.B., Soares, A.M.V.M., Loureiro, S., 2010. Basal levels of enzymatic biomarkers and energy reserves in Porcellionides pruinosus. Soil Biol. Biochem. 42, 2128-2136.

Fischer, E., Farkas, S., Hornung, E., Past, T., 1997. Sublethal effects of an organophosphorus insecticide, dimethoate, on the isopod Porcellio scaber. Latr. Comp. Biochem. Physiol. 116 C (2), 161-166.

Filzek, P.D.B., Spurgeon, D.J., Broll., G., Svendsen, C., Hankard, P.K., Parekh, N., Stubberud, H.E., Weeks, J.M., 2004. Metal effects on soil invertebrate feeding: measurements using the bait lamina method. Ecotoxicology 13, 807-816.

FOCUS, 2007. Soil Persistence Models and EU Registration. The Final Report of the Work of the SOIL Modelling WG of FOCUS.

Gange, A.C., Brown, V.K., Farmer, L.M., 1992. Effects of pesticides on the germination of weed seeds: implications for manipulated experiments. J. Appl. Ecol. 29, 3030-3100.

Giller, K.E., Beare, M.H., Lavelle, P., Izac, A.-M.-N., Swift, M.J., 1997. Agricultural intensification, soil biodiversity and agroecosystem function. Appl. Soil Ecol. 6, 3-16.

Guilhermino, L., Lopes, M.C., Carvalho, A.P., Soares, A.M.V.M., 1996. Inhibition of acetylcholinesterase activity as effect criterion in acute tests with juvenile Daphnia magna. Chemosphere 32, 727-738.

Habig, W.H., Pabst, M.J., Jakoby, W.B., 1974. Glutathione S-transferases-first enzymatic step on mercapturic acid formation. J. Biol. Chem. 249, 7130-7139.

Huangfu, C.H., Song, X.L., Qiang, S., Zhang, H.J., 2007. Response of wild Brassica juncea populations to glyphosate. Pest Manage. Sci. 63 (11), 1133-1140.

Jemec, A., Drobne, D., Tisler, T., Sepcić, K., 2010. Biochemical biomarkers in environmental studies-lessons learnt from enzyme catalase, glutathione $S$-transferase and cholinesterase in two crustacean species. Environ. Sci. Pollut. Res. Int. 17 (3), 571-581.

Jonker, M.J., Svendsen, C., Bedaux, J.J.M., Bongers, M., Kammenga, J.E., 2005. Significance testing of synergistic/antagonistic, dose level-dependent, or dose ratio-dependent effects in mixture dose-response analysis. Environ. Toxicol. Chem. 24, 2701-2713.

Köneman, W.H., Pieters, M.N., 1996. Confusion of concepts in mixture toxicology. Food Chem. Toxicol. 34 (11-12), 1025-1031.

Kratz, W., 1998. The bait-lamina test. General aspects, applications and perspectives. Environ. Sci. Pollut. Res. 5 (2), 94-96.

Kools, S.A.E., Boivin, M.-E.,Y., Van der Wuff, A.W.G., Berg, M.P., Van Gestel, C.A.M., Van Straalen, N.M., 2009. Assessment of structure and function in metal polluted grasslands using terrestrial model ecosystem. Ecotoxicol. Environ. Saf. 72 (1), 51-59.
Kula, C., Römbke, J., 1998. Evaluation of soil ecotoxicity tests with functional endpoints for the risk assessment of plant protection products. Environ. Sci. Pollut. Res. 5, 55-60.

Langdon, C.J., Hoson, M.E., Arnold, R.E., Black, S., 2005. Survival, Pb-uptake and behaviour of three species of earthworms in $\mathrm{Pb}$ treated soils determined using and OECE-style toxicity test and a soil avoidance test. Environ. Pollut. 138, $368-375$.

Lavelle, P., Bignell, D., Lepage, M., Wolters, V., Roger, P., Ineson, P., Heal, O.W., Dhillion, S., 1997. Soil function in a changing world: the role of invertebrate ecosystem engineers. Eur. J. Soil Biol. 33, 159-193.

Lemos, M.F.L., van Gestel, C.A.M., Soares, A.M.V.M., 2010. Developmental toxicity of endocrine disrupters bisphenol A and vinclozolin in a terrestrial isopod. Arch. Environ. Contam. Toxicol. 59, 274-281.

Loureiro, S., Sousa, J.P., Nogueira, A.J.A., Soares, A.M.V.M., 2002. Assimilation efficiency and toxicokinetics of ${ }^{14} \mathrm{C}$-lindane in the terrestrial isopod Porcellionides pruinosus: the role of isopods in degradation of persistent soil pollutants. Ecotoxicol. 11, 481-490.

Løkke, H., Van Gestel, C.A.M., 1998. Handbook of Soil Invertebrate Toxicity Tests. John Wiley and Sons Wiley, Chichester.

Loureiro, S., Sousa, J.P., Soares, A.M.V.M., Nogueira, A.J.A., 2005a. Assimilation efficiency and toxicokinetics of ${ }^{14} \mathrm{C}$-lindane in the terrestrial isopod Porcellionides pruinosus: the role of isopods in degradation of persistent soil pollutants. Ecotoxicology 11, 481-490.

Loureiro, S., Soares, A.M.V.M., Nogueira, A.J.A., 2005b. Terrestrial avoidance behaviour tests as screening tool to assess soil contamination. Environ. Pollut. $138,121-131$.

Loureiro, S., Svendsen, C., Ferreira, A.L.G., Pinheiro, C., Ribeiro, F., Soares, A.M.V.M., 2010. Toxicity of three binary mixtures to Daphnia magna: comparing chemicals mode of action and deviations from conceptual models. Environ. Toxicol. Chem. 29, 1716-1726.

Ludke, J.L., Hill, E.F., Dieter, M.P., 1974. Cholinesterase (ChE) response and related mortality among birds fed ChE inhibitors. Arch. Environ. Contam. Toxicol. 3, 1.21

Lukkari, T., Teno, S., Väisänen, A., Haimi, J., 2006. Effects of earthworms on decomposition and metal availability in contaminated soil: microcosm studies of populations with different exposure histories. Soil Biol. Biochem. 38, 359-370.

Marrs, R.H., William, C.T., Frost, A.J., Plant, R.A., 1989. Assessment of the effects of herbicide spray drift on a range of plant species of conservation interest. Environ. Pollut. 59, 71-86.

Martin, H.L., Svendsen, C., Lister, L.J., Gomez-Eyles, J.L., Spurgeon, D.J., 2009. Measurement and modeling of the toxicity of binary mixtures in the nematode Caenorhabidtis elegans - a test for independent action. Environ. Toxicol. Chem. 28, 97-104.

Matsumura, F., 1987. Comparative metabolism of mixtures of chemicals by animals, plants and microorganisms and their significance in alteration of pollutants in the environment. In: Vouk., V.B., Buttler, G.C., Upton, A.C., Parke, D.V., Asher, A.C. (Eds.), Methods for Assessing the Effects of Mixtures of Chemicals. John Wiley and Sons, Chichester, pp. 509-522.

Ohkawa, H., Ohishi, N., Yagi, K., 1979. Assay for lipid peroxides in animal e tissues by thiobarbituric acid reaction. Anal. Biochem. 95, 351-358.

Reinecke, A.J., Helling, B., Louw, K., Foursie, J., Reinecke, S.A., 2002. The impact of different herbicides and cover crops on soil biological activity in vineyards in the Western Cape, South Africa. Pedobiologia 46, 475-484.

Santos, M.J.G., Soares, A.M.V.M., Loureiro, S., 2010a. Joint effects of three plant protection products to the isopod Porcellionides pruinosus and the collembolan Folsomia candida. Chemosphere 80, 1021-1030.

Santos, M.J.G., Ferreira, N.G.C., Soares, A.M.V.M., Loureiro, S., 2010b. Toxic effects of molluscicide baits to the terrestrial isopod Porcellionides pruinosus. J. Soils Sediments 10, 1335-1343.

Santos, M.J.G., Ferreira, V., Soares, A.M.V.M., Loureiro, S., 2011a. Evaluation of the combined effects of dimethoate and spirodiclofen on plants and earthworms in a designed microcosm experiment. Appl. Soil Ecol. 48, 294-300.

Santos, M.J.G., Soares, A.M.V.M., Loureiro, S., 2011b. Triticum aestivum (L.) and Brassica rapa (L.). J. Soils Sediment. doi:10.1007/s11368-011-0393-9.

Snoo, G.R., Wit, P.J., 1998. Buffer zones for reducing pesticide drift to ditches and risk to aquatic organisms. Ecotoxicol. Environ. Saf. 41, 112-118.

Sousa, J.P., Loureiro, S., Pieper, S., Frost, M., Kratz, W., Nogueira, A.J.A., Soares, A.M.V.M., 2000. Soil and plant diet exposure routes and toxicokinetics of lindane in a terrestrial isopod. Environ. Toxicol. Chem. 19, 2557-2563.

Svendsen, C., Siang, P., Lister, L.J., Rice, A., Spurgeon, S.J., 2010. Similarity, independence, or interaction for binary mixture effects of nerve toxicants for the nematode Caenorhabditis elegans. Environ. Toxicol. Chem. 29, 1182-1191.

Syers, J.K., Springett, J.A., 1984. Earthworms and soil fertility. Plant Soil 76, 93-104.

Van Gestel, C.A.M., Kruidemier, M., Berg, M., 2003. Suitability of wheat straw decomposition, cotton strip degradation and bait-lamina feeding tests determine soil invertebrate activity. Biol. Fertil. Soils 37, 115-123.

Valant, J., Drobne, D., Sepčić, K., Jemec, A., Kogej, K., Kostanjšek, R., 2009. Hazardous potential of manufactured nanoparticles identified by in vivo assay. J. Hazard. Mater. 171, 160-165.

Verrel, P., Van Buskir, E., 2004. As the worm turns: Eisenia fetida avoids soil contaminated by a glyphosate-based herbicide. Bull. Environ. Contam. Toxicol. 72, 219-224.

Wauchope, R.D., Buttler, T.M., Hornsby, A.G., Augustin-Beckers, P.W.M., Burt, J.P., 1992. Pesticide properties database for environmental decisionmaking. Rev. Environ. Contam. Toxicol. 123, 1-157. 